Instrumental Background

\section{Stopping the Sun: Stay Still, Won't You?}

\author{
Charles Mollan
}

Whether you believe that the Earth goes round the sun or that the sun goes round the Earth, you have a problem when you want a nice bright steady sunbeam to illuminate your scientific experiment. The snag is that the sunbeam won't stand still. Imagine you're a scientist working in 1820 and you have just set up your microscope to study a new form of life or a previously unknown mineral. You have to use reflected sunlight to illuminate it as no other adequate form of intense lighting is available. It is a beautiful cloudless day (so you are more likely to be in France than in Ireland), you are poised to make a momentous discovery, but the reflected light has moved on. A certain level of illumination is needed before the specimen will reveal its secrets. But unless you keep moving the mirror you won't have long to study the specimen at all.

Life would be easier if you had four hands, one to focus the microscope, one to adjust the position of the specimen, one to move the mirror, and one to draw or make notes on the image. These days an extra pair of hands is usually available in the form of a willing $\mathrm{PhD}$ student. But these weren't so readily available in 1820 . Of course, if you are a gentleman or lady scientist with a selection of house servants you can delegate one to move the mirror for you. But maybe he has been at the port again, and his hand is shaking. Anyway, communication between the classes does not have an encouraging history. You thus have a problem crying out for a solution.

One approach would have been to invent intense electric light, but while work was progressing towards this end another solution was needed in the meantime. The solution was the clockwork mirror. The clockwork mirror relies on the convenient fact that although the sun apparently moves it does so at a pretty constant rate. Clockwork was well devel-

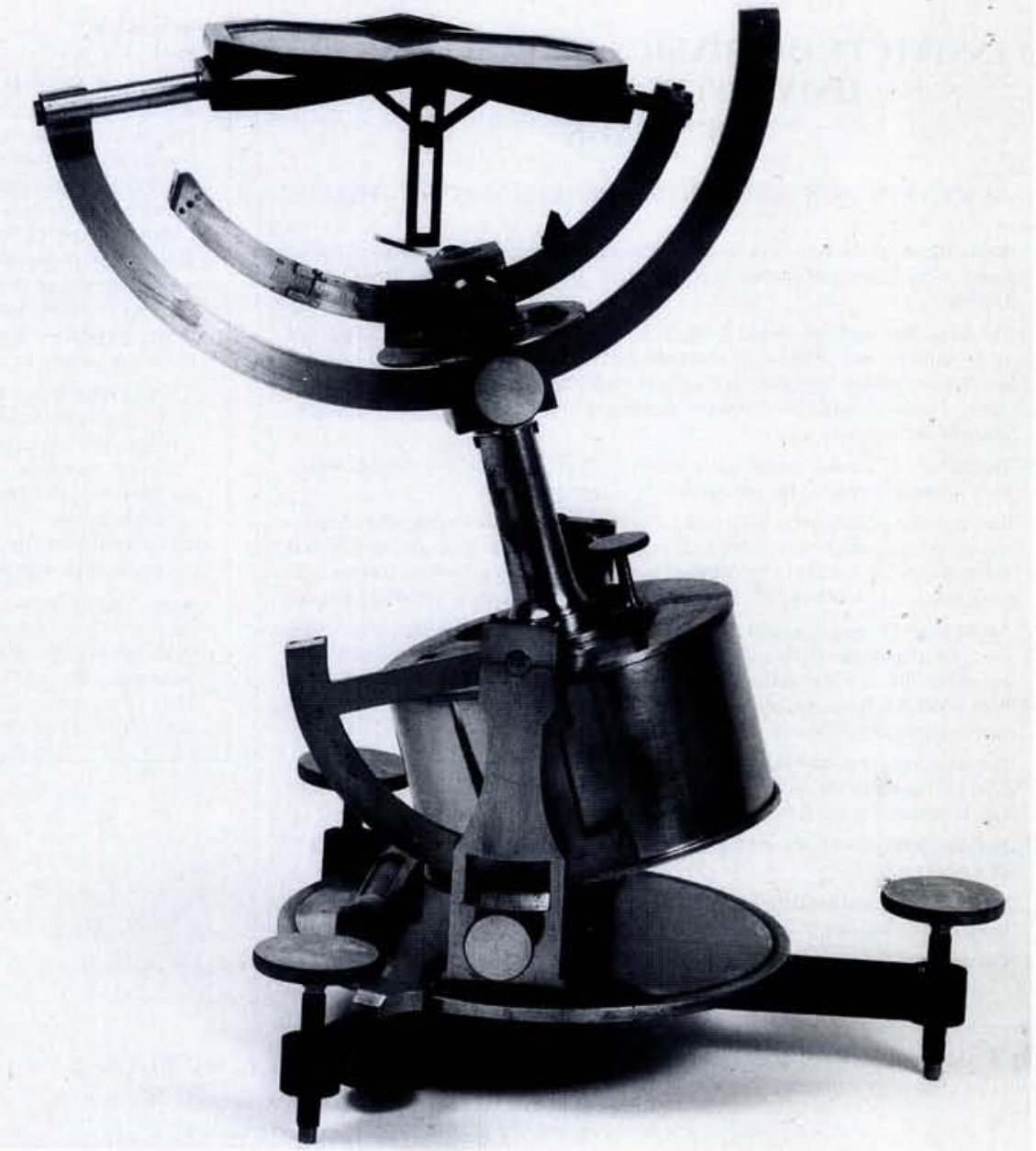

oped by the nineteenth century, so the challenge was devising a clockwork device which would revolve a mirror at just the right speed and keep it at the right orientation to ensure a steady sunbeam.

There were several people who rose to the challenge of devising 'heliostats' as they are called because they were designed to stop the sun. The best known, and arguably the most elegant, heliostat was invented by Frenchman Johann Silbermann in 1843 (figure 1) and manufactured in considerable numbers by the famous Paris instrument maker Jules Duboscq. The clockwork is contained in a cylinder whose axis can be adjusted to coincide with the polar axis of the location. A mechanism coupled to the mirror has two arcs, the upper one set to the declination of the sun, and the other intended to direct the beam to where it was needed. While this was a very neat solution it had two disadvantages: only a small mirror could be used and the couplings were not very stable.

Sacrificing beauty, the famous Leon Foucault (of pendulum fame) invented an
Fig 1 The elegant heliostat of Johann Silbermann, signed by Jules Duboscq, Paris, from the collection of the Physics Department, The Queen's University of Belfast

improved form in 1862 . He mounted his comparatively large mirror (figure 2) on a sturdy column of its own thus producing a much more rigid arrangement. Indeed, this idea worked so well that it was, in much more massive form, used for astronomical work.

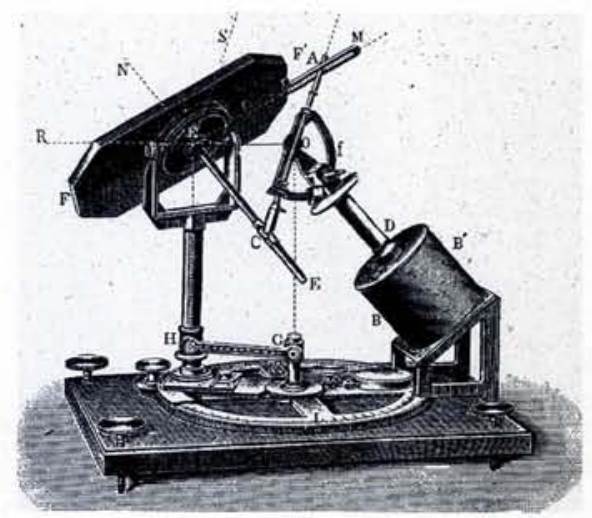

Fig 2 The heliostat of Leon Foucault (1819-1868) 